EDITORIAL

\title{
Un año enfrentando y conociendo la COVID-19
}

\author{
A year facing and getting to know COVID-19
}

La COVID-19 es tan enigmática como devastadora. Inundó de información científica el mundo médico y sigue su desarrollo, nos demostró la importancia de la prevención, nos enseñó a revisar la historia y a tomar el ritmo de la lectura científica minuto a minuto. A un año de haberse declarado la pandemia, el tema sigue en el primer lugar de actualidad en el mundo, habiéndose confirmado más de 146 millones de casos y 3 millones de fallecidos, en 185 países cuyo sistema de salud ha enfrentado desafíos sin precedentes.

La COVID-19 delató el abandono del sistema sanitario hondureño y expuso las enormes necesidades de recursos profesionales y técnicos tanto en número como en variedad, reveló las condiciones de trabajo, la carencia de equipos, insumos y fármacos; haciendo obligatorio reemprender con logros para la cobertura universal de salud y facilitar el acceso a la población. ${ }^{2}$ Después de un año de pandemia se ha reconocido que las únicas estrategias de contención de contagio comunitarias, efectivas, son el confinamiento domiciliario y la práctica repetitiva de medidas higiénicas, el distanciamiento físico y el uso de mascarilla. Ha sido necesario educar a la población en lo confirmado a través de evidencia científica y exigiendo ignorar mensajes falsos que circulan en las redes sociales anunciando métodos preventivos o curativos que no tienen ningún fundamento científico. ${ }^{3}$

Se ha contabilizado mayor transmisión en los hombres, afectando más frecuentemente adultos y adultos mayores, con comorbilidades, por ejemplo, obesos, individuos con hipertensión arterial y diabetes mellitus. Más del $80 \%$ de los pacientes presenta manifestaciones clínicas leves y un grupo cursa asintomático. Las formas más graves de la enfermedad las adolece el $15 \%$, quienes presentan afección de la función respiratoria, requiriendo ventilación no invasiva con aportes de oxigeno de alto flujo, continuando con el síndrome de respuesta inflamatoria sistémica con probabilidades de aparición de choque distributivo e insuficiencia multiorgánica, con una elevada tasa de mortalidad. ${ }^{4,5}$ Ante la escasez de métodos diagnósticos en nuestro país, en la mayoría de los casos se consideró el juicio clínico a través de la anamnesis y la exploración física para la toma de decisiones, clasificándoles caso confirmado a quienes se les realizó la pruebas de PCR TR, existiendo la gran necesidad de pruebas accesibles y de rápidos resultados.

A la fecha, abril 2021, no existe un tratamiento específico para la COVID-19. El abordaje consiste en proveer apoyo sintomático, incluyendo apoyo respiratorio mecánico en los casos más graves quienes son tratados de manera compasiva con drogas que están en experimentación clínica. Se ha experimentado con múltiples fármacos con efecto antiviral y antinflamatorio, pero se requiere más tiempo para comprobar su efectividad. En resumen, el remdesivir, un análogo de nucleótidos con actividad contra varios virus ARN ha demostrado mejoría clínica rápida si se administra tempranamente enumerándose entre los medicamentos recomendados actualmente por la Agencia Española de Medicamentos y Productos Sanitarios para el tratamiento de pacientes hospitalizados, seguido por tocilizumab y dexametasona, siendo los únicos que han constatado reducción de la mortalidad. De no haber contraindicaciones, se recomienda profilaxis antitrombótica con heparinas de bajo peso molecular. $^{6}$

La tasa de mortalidad del personal médico en Honduras es más alta que en la población general, y la mayor mortalidad es en adultos mayores, directamente proporcional a la edad, empeorando con las comorbilidades. Actualmente requerimos de la producción a gran escala de vacunas, para inmunizar la mayoría de la población, pretendiendo reducir las consecuencias físicas, psicológicas, sociales y económicas que en forma global ha impuesto la COVID-19. De no dar resultados efectivos y seguros, es probable que lo peor esté por verse.

Helga Indiana Codina

Reumatóloga, Secretaria de Actas y Correspondencia

Junta Directiva Colegio Médico de Honduras 2020-2022

\section{REFERENCIAS}

1. Johns Hopkins University. Coronavirus Resource Center. Mortality Analyses. [Internet]. Maryland: Johns Hopkins University; 2020. [consultado 25 abril 2021]. Disponible en: https://coronavirus.jhu.edu/map.html

2. Cassiani SHB, Munar Jimenez EF, Umpiérrez Ferreira A, Peduzzi M, Leija Hernández C. La situación de la enfermería en el mundo y la Región de las Américas en tiempos de la pandemia de COVID-19. Rev Panam Salud Publica [Internet]. 2020[consultado 25 abril 2021];44:e64. Disponible en: https://doi. org/10.26633/RPSP.2020.64

3. Bedford J, Enria D, Giesecke J, Heymann DL, Ihekweazu C, Kobinger G, et al. COVID-19: towards controlling of a pandemic. Lancet. 2020;395(10229):1015-1018.

4. Madrigal J, Quezada M, García M, Solano A. SARS CoV-2, manifestaciones clínicas y consideraciones en el abordaje diagnóstico de COVID-19. Revista Médica de Costa Rica.2020;85:13-21.

5. Cespedes M, Bell J, Romero D, Ferrales N. La COVID en personas hipertensas. MEDISAN. 2020;24(3): 501-514.

6. Llover MN, Jiménez MC. Estado actual de los tratamientos para la COVID-19. FMC. 2021;28(1):40-56. 